\title{
Lymphadenopathy and systemic lupus erythematosus
}

\author{
Nilton Salles Rosa Neto ${ }^{1}$, Karina Rossi Bonfiglioli ${ }^{1}$, Fernanda Manente Milanez ${ }^{1}$,
} Patrícia Andrade de Macêdo ${ }^{1}$, Maurício Levy-Neto²

\begin{abstract}
Lymphadenopathy is a benign finding in systemic lupus erythematosus (SLE), commonly seen in young patients with cutaneous involvement and constitutional symptoms, with good response to corticosteroids. Reactive follicular hyperplasia is the most frequent finding in biopsies. We report the case of a patient with recurrent episodes of lymphadenopathy associated with hepatosplenomegaly, fever, and weight loss since the age of 13 years. The patient also developed arthritis, hypertension, proteinuria, cardiomyopathy, and peripheral neuropathy. His condition was investigated extensively without diagnostic clarification; he was treated, empirically, for tuberculosis. The patient received a diagnosis of SLE only five years after the original presentation and received the specific treatment. Early diagnosis in those cases is difficult because laboratorial exams may not show the presence of auto-antibodies and low complement levels.
\end{abstract}

Keywords: systemic lupus erythematosus, fever of unknown origin, wasting syndrome, auto-antibodies, lymphadenopathy.

\section{INTRODUCTION}

Lymphadenopathy is characterized by changes in the number, characteristics, or size of the lymph nodes. It results from reticuloendothelial proliferation secondary to inflammation, infection, or malignancies. In systemic lupus erythematosus (SLE) it represents a benign finding, with a mononucleosislike behavior, and it can be seen in any phase of the disease. ${ }^{1-3}$

Biopsy commonly shows reactive follicular hyperplasia (RFH), with or without atypical cells, and it is considered a non-specific finding. Coagulative necrosis with hematoxylin bodies, typical findings in SLE, is rarely seen..$^{4,5}$

We report the case of a patient with recurrent episodes of lymphadenopathy treated initially as infectious in origin, who was later diagnosed with SLE.

\section{CASE REPORT}

This is an 18 years old male patient from São Paulo, SP. In 2003, the patient developed recurrent episodes of lymphadenomegaly, hepatomegaly, fever in the evening, diaphoresis, and weight loss, lasting several months and with spontaneous regression.
In 2004, the patient developed anasarca, which subsided, and hypertension, which persisted. In the following year the patient developed arthritis in the knees. At that time, rheumatoid factor and anti-nuclear factor (ANF) were negative and complement levels were normal.

Repeated biopsy of the lymph nodes showed RFH, and investigation for tuberculosis was negative. He had a PPD of $5 \mathrm{~mm}$ and normal chest X-ray, but the team responsible for his cared instituted treatment for tuberculosis (rifampin, isoniazid, and pyrazinamide). With recurrence of the symptoms, ethambutol was added to the regimen for therapeutic failure. After a new recurrence in 2008 associated with polyarthritis and proximal muscular weakness, the patient was referred to the reference hospital due to refractory tuberculosis, where pleural and pericardial effusion, hepatosplenomegaly, and generalized lymphadenomegaly, along with a $20-\mathrm{kg}$ weight loss, were identified.

After ruling out infectious causes, a new lymph node biopsy showed RFH (Figure 1). This time the ANF was positive and the patient was referred to a rheumatologist.

Laboratory test revealed anemia of chronic disease, normal muscle enzymes, proteinuria of $1.99 \mathrm{~g} / 24$ hours without

Received on 01/19/2009. Approved on 10/06/2009. We declare no conflict of interest.

Rheumatology Department of the University Hospital of the Medical School of Universidade Federal de Mato Grosso do Sul (FAMED - UFMS)

1. Rheumatology Residents of Hospital das Clínicas of the Medical School of Universidade de São Paulo (HC-FMUSP)

2. Physician of the Rheumatology Department of HC-FMUSP

Correspondence to: Dr. Maurício Levy-Neto. Disciplina de Reumatologia, FMUSP. Av. Dr. Arnaldo, 455, 3º andar, sala 3133, CEP 01246-903, Cerqueira César,

São Paulo, SP, Tel: 5511 3061-7492, Fax: 5511 3061-7490. E-mail: levy.neto@hcnet.usp.br 


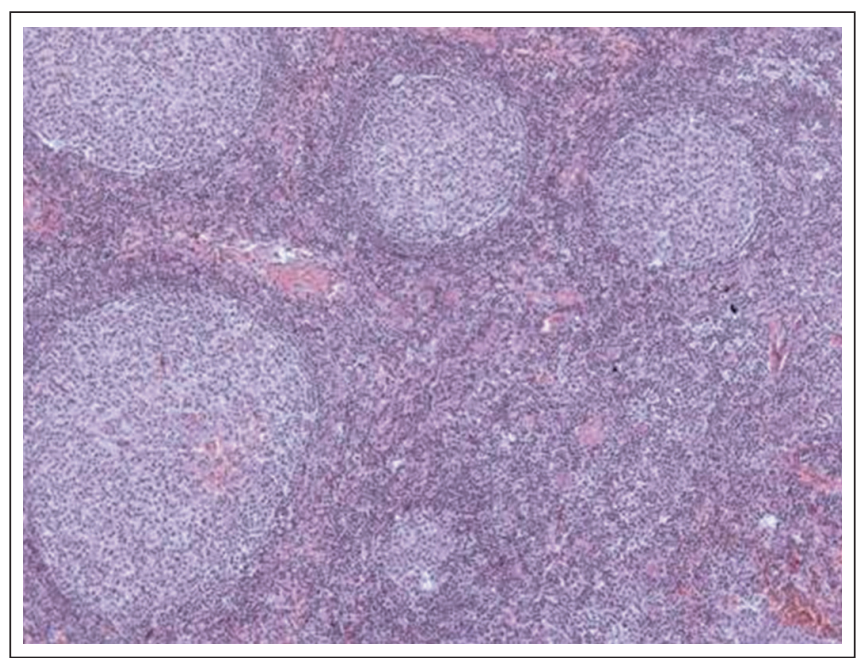

Figure 1. Histologic section of a cervical lymph node showing reactive lymphoid hyperplasia. Hematoxylin-eosin. 100x.

hematuria/leukocyturia, and elevated inflammatory acute phase reactants. The ultrasound scan showed parenchymatous nephropathy, and the echocardiogram showed diffuse hypokinesis and ejection fraction $55 \%$ (in a previous exam it was higher than 70\%). Electroneuromyography showed chronic peripheral neuropathy without evidence of myopathy. Neoplastic causes were ruled out.

The patient had positive ANF with a speckled pattern (titer higher than 1/320), and positive anti-Ro, anti-P, and IgG and IgM anticardiolipin antibodies. Kidney biopsy showed membranous glomerulonephritis.

The patient received the diagnosis of SLE and treatment with prednisone, $60 \mathrm{mg} / \mathrm{d}$, chloroquine diphosphate, $250 \mathrm{mg} / \mathrm{d}$, and azathioprine, $100 \mathrm{mg} / \mathrm{d}$, was instituted. The patient is currently asymptomatic and on decreasing doses of prednisone.

\section{DISCUSSION}

The clinical presentation and evolution of SLE shows a wide variety. The immunopathogenesis of SLE is associated with genetically determined loss of self-tolerance and cellular activation dependent of non-genetic factors, such as environmental, hormonal, and infectious. Activation of $\mathrm{T}$ lymphocytes by $\gamma$-interferon stimulates the sequence of progressive and persistent expansion of apoptosis-resistant polyclonal B lymphocytes, which produce auto-antibodies characteristics of the disease. ${ }^{6}$

Lupus lymphadenopathy (LL) has an estimated prevalence between 5 and $7 \%$, at the onset of the disease, and 12 to $15 \%$, at stage of the disease. ${ }^{7,8}$ Lupus lymphadenopathy involves, mainly, the cervical and axillary regions, and the lymph nodes are soft, mobile, painful, and non-adherent to deep planes. ${ }^{2}$ In case of significant lymphadenopathy, lymph node biopsy is indicated to rule out infectious or lymphoproliferative disorders. ${ }^{1-3}$ Table 1 includes the most important differential diagnosis in those cases.

Lupus lymphadenopathy can be classified as localized (involvement of up to two lymph node chains) or generalized (three or more). Findings of malar erythema, photosensitivity, alopecia, oral ulcers, fever, weight loss, nocturnal sudoresis, and hepatosplenomegaly are expected. Kojima et al. ${ }^{5}$ demonstrated a higher incidence of LL in women, association with systemic symptoms and altered laboratorial exams, and RFH on histology. However, they identified atypical histological characteristics and classified them as:

- RFH with giant follicles: irregular follicles, increased in size, with hyperplastic germinal center, and cytolysis.

- Aspects similar to Castleman's disease (CD): plasmacytosis and interfollicular vascular proliferation; it might be mistaken for the mixed form of CD.

- Atypical paracortical hyperplasia with lymphoid follicles: immunohistochemistry (IH) allows differentiating it from angioimmunoblastic $\mathrm{T}$ cell lymphoma. It is associated with fever, polyclonal hypergammaglobulinemia, and circulating immune complexes.

- Atypical immunoblastic and lymphoplasmacytic proliferation: lymphoplasmacytic and policlonal B-immunoblastic infiltration; without lymphoid follicles or vascular proliferation.

A classification of the patterns of lymph node lesions in SLE, similar to the classes of lupus nephritis, has been suggested; however, those types do not seem to be specific enough to establish the diagnosis of SLE. ${ }^{4}$

The increased risk of lymphomas, especially nonHodgkin's lymphoma, in lupus patients led to further studies of those atypical changes. The symptoms of both disorders can be similar, which can delay the diagnosis and treatment of the neoplasia. Complete differentiation depends on IH.9-12

Kikuchi-Fujimoto disease (KFD), or histiocytic necrotizing lymphadenitis, a self-limiting disease of young people, involving mainly cervical lymph nodes, should also be ruled out. Its histological characteristics allow recognizing it as a specific disease. Its development before, after, or concomitantly to the diagnosis of SLE has been reported. Since LL courses with coagulative necrosis, it raises doubts on the cases reported in the literature as the association of SLE and KFD. The 
Table 1

Differential diagnosis of lymphadenopathy

\begin{tabular}{ll}
\hline Infections & $\begin{array}{l}\text { Cytomegalovirus, Epstein-Barr virus, HIV, } \\
\text { Toxoplasmosis, Tuberculosis }\end{array}$ \\
Drugs & $\begin{array}{l}\text { Captopril, Penicillamine, Hydralazine, } \\
\text { Phenytoin, Gold salts }\end{array}$ \\
\hline Inflammatory diseases & $\begin{array}{l}\text { Sarcoidosis, Still's Disease, SLE, Rheumatoid } \\
\text { Arthritis, Kikuchi-Fujimoto disease }\end{array}$ \\
\hline Neoplasia & Lymphoma \\
\hline
\end{tabular}

differential diagnosis between those two entities requires $\mathrm{IH}$ of all suspicious lymph nodes because LL has a very small number of cytotoxic $\mathrm{T}$ cells while KFD has a high number of those cells. ${ }^{13}$

In summary, lymphadenopathy is a common manifestation in SLE. As illustrated by the case presented here, it can antecede the diagnosis of SLE by many years, when the presence of ANF, other auto-antibodies, or low complement levels cannot be detected. It is possible that the factors that induce lymph node proliferation are also responsible for the development of auto-antibodies.

\section{REFERÊNCIAS}

\section{REFERENCES}

1. Shapira Y, Weinberger A, Wysenbeek AJ. Lymphadenopathy in systemic lupus erythematosus. Prevalence and relation to disease manifestations. Clin Rheumatol 1996; 5(4):335-8.

2. Melikoglu MA, Melikoglu M. The Clinical Importance of Lymphadenopathy in Systemic Lupus Erythematosus. Acta Reumatol Port 2008; 33:402-6.
3. Calguneri M, Ozturk MA, Ozbalkan Z, Akdogan A, Ureten K, Kiraz $\mathrm{S}$ et al. Frequency of Lymphadenopathy in Rheumatoid Arthritis and Systemic Lupus Erythematosus. J Int Med Res 2003; 31:345-9.

4. Kojima M, Nakamura S, Morishita Y, Itoh H, Yoshida K, Ohno Y et al. Reactive follicular hyperplasia in the lymph node lesions from systemic lupus erythematosus patients; a clinicopathological and immunohistological study of 21 cases. Pathol Int 2000; 50:304-312.

5. Kojima M, Motoori T, Asano S, Nakamura S. Histological diversity of reactive and atypical proliferative lymph node lesions in systemic lupus erythematosus patients. Pathol Res Pract 2007; 203(6):423-31.

6. Koutouzov S, Mathian A, Dalloul A. Type-I interferons and systemic lupus erythematosus. Autoimmun Rev 2006; 5(8):554-62.

7. Cervera R, Khamashta MA, Font J, Sebastiani GP, Gil A, Lavilla $\mathrm{P}$ et al. Systemic lupus erythematosus: clinical and immunologic patterns of disease expression in a cohort of 1,000 patients. The European Working Party on Systemic Lupus Erythematosus. Medicine (Baltimore) 1993; 72(2):113-24.

8. Pons-Estel BA, Catoggio LJ, Cardiel MH, Soriano ER, Gentiletti $\mathrm{S}$, Villa AR et al. The GLADEL multinational Latin American prospective inception cohort of 1,214 patients with systemic lupus erythematosus: ethnic and disease heterogeneity among "Hispanics". Medicine (Baltimore) 2004; 83(1):1-17.

9. Hansen A, Lipsky PE, Dörner T. B-cell lymphoproliferation in chronic inflammatory rheumatic diseases. Nat Clin Pract Rheumatol 2007; 3(12):561-9.

10. Bernatsky S, Ramsey-Goldman R, Rajan R, Boivin JF, Joseph L, Lachance $\mathrm{S}$ et al. Non-Hodgkin's Lymphoma in Systemic Lupus Erythematosus. Ann Rheum Dis 2005; 64:1507-9.

11. Bernatsky S, Ramsey-Goldman R, Isenberg D, Isenberg D, Rahman A, Dooley MA, Sibley J et al. Hodgkin's Lymphoma in Systemic Lupus Erythematosus. Rheumatology 2007; 46:830-2.

12. Smedby KE, Baecklund E, Askling J. Malignant Lymphomas in Autoimmunity and Inflammation: a Review of Risks, Risk Factors and Lymphoma Characteristics. Cancer Epidemiol Biomarkers Prev 2006; 15(11):2069-77.

13. Hu S, Kuo TT, Hong HS. Lupus lymphadenitis simulating Kikuchi's lymphadenitis in patients with systemic lupus erythematosus: a clinicopathological analysis of six cases and review of the literature. Pathol Int 2003; 53:221-6. 